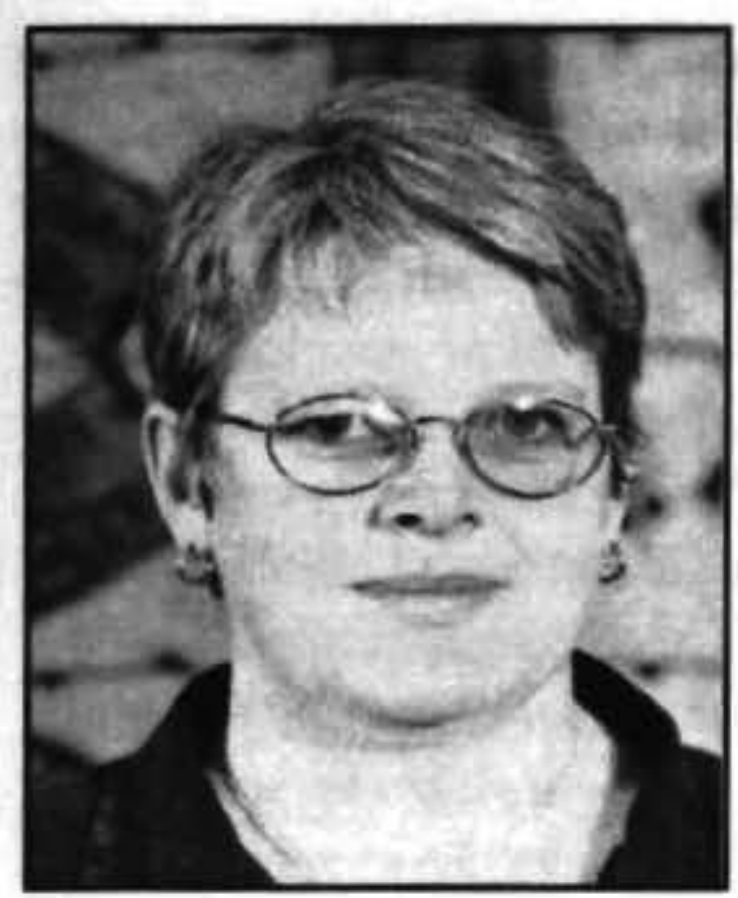

\title{
EQUITY ISSUES IN WORK/LIFE BALANCE PROGRAMMES
}

\author{
Avette Kelly \\ Recreation and Community Services \\ Auckland City Council
}

In the past 10 years there has been an increasing number of works published detailing the positive impact of familyfriendly and work/life balance programmes on workplace culture and performance. While this study does not attempt to refute this body of literature, it does address an issue which has been largely ignored thus far. That is, that work/life programmes with an emphasis on family-friendly initiatives can leave some staff members feeling disadvantaged and create a subculture of dissatisfaction. This paper examines whether these feelings exist in a small sample of New Zealand companies. Staff from two groups within Auckland City Council were surveyed and an email questionnaire was sent to a non-random sample of childless employees from 10 other firms. These results of these surveys did not find evidence to support the idea that many childless staff feel disadvantaged by family-friendly initiatives especially where the programmes were flexible and could be used by anyone who needed them.

Keywords: Equity, work place culture

In New Zealand and overseas the balance between work and life is becoming an important issue for more and more employees (Galinsky, Bond, \& Friedman, 1996; Hooks, 1996; Kramar, 1997). Ironically, in an era where many profit driven organisations are becoming leaner, expecting people to work harder for longer and making it more difficult for managers and workers to survive (Vannoy, 1998), employees are increasingly staking their claim for a life outside of work. What's more, for a variety of reasons, from ethical to pragmatic, a growing number of organisations are introducing policies to help their employees attain a balance between a demanding work schedule and actually having a life. The desire to attract and retain skilled staff is often cited as one reason for developing a suite of work/life programmes (Stamps, 1997; Vannoy \& Dubeck, 1998; Wolcott \& Glezer, 1995). In a survey of senior human resource executives conducted by the American Management Association in 1999, 60 \% of those surveyed said that skilled manpower is scarce. The same survey found that where companies did have retention programmes in place, lifestyle and educational incentives were more effective that monetary compensation.

In the last decade there has been a growth industry in material dealing with work/life balance issues. In conducting a literature search using the parameters 'work and life' approximately three quarters of the material I found was published after 1990. It was while doing this search I noticed another interesting phenomenon. Much of the literature focused on one aspect of work/life, being family-friendly. Indeed, over two thirds of the titles and abstracts found included the word family. A similar proportion was found when searching for books rather than articles. It seemed that for many writers, researchers and or- ganisations, work/life was synonymous with familyfriendly. As a full-time working mother I had absolutely no problem with this, but it did give me pause for thought. If I were not a parent, would I still feel that the organisation I worked for was considering my need to have a life outside of work? With this in mind I continued my search and found, dotted through this vast array of literature concerning family-friendly work practices, a small number of articles that raised this very question (Jenner, 1994a, 1994b; Picard, 1997). In focussing on the needs of those with families were employers alienating those employees who did not have dependent care responsibilities?

This raised other questions. If there is a case to be made that some employees feel resentful of the focus on family-friendly programmes, what can be done to redress this? Are there programmes that will meet the needs of a wider range of employees in managing the demands of work and life? How can employers ascertain that their programmes are having the desired effect, whatever that may be (loyalty, retention, reduction in absenteeism, higher morale, increased production)?

The literature around the issue of childless employees was all written in America. In order to look at the issue from a (limited) New Zealand perspective I formulated the following questions. Is there a perceived lack of equity in the programmes and benefits offered to achieve work/life balance (Deutsch, 1975; Rothausen, Gonzalez, Clarke, \& O'Dell, 1998)? If so, what measures could be taken to remedy this? To begin to answer these questions a pilot study was conducted amongst two groups of employees at Auckland City Council and a sample of childless people from a variety of other organisations. The findings of 
this study will be outlined later in this paper.

For the purpose of this study I have defined the term equity to mean fairness as in much of the literature concerning perceived inequities the complaints seem to be based around not being treated fairly or having access to the same rights as those with families. Work/life programmes are any initiatives which are designed to help employees feel that they have a sense of balance between work and home.

\section{Literature Review}

As stated previously, there is a great deal of literature available on the area of work/life balance. A large proportion of that literature deals with why work/life programmes are important both to the individual and the employer, what they are and how they can be implemented. They cover issues ranging from retaining women in the paid workforce to child and elder care and the needs of the working father (Bernardi 1999; Clarke 1999; Hooks 1996; Kehan 2000; Law 1998, Schrage 1999).

In New Zealand the EEO Trust has produced several resources on integrating family-friendly policies into the workplace inclusing 'Work and family: a guide for managers' and 'Work and family: steps to success'. There are also some excellent books available. In 'Breaking the mold: women, men and time in teh new corporate word' Bailyn (1993) argues that corporate America will need to radically rethink its basic assumptions about the way people work if business is to succeed in the twenty first century. In particualr she asks, 'why is visibility - presence at work - such a critical indicator of commitment' (Bailyn 1993:2-3). This alone could produce a whole research project, as could issues raised in Irene Wolcott's 'Small business vies of work and family' (1993) which looks at how small buisnesses handle the needs of employees (and owners) to manage work/family balance.

Despite the temptations of issues found in other works, it was an issue raised in a small number of articles dispersed amongst the wide range of literature advocating work/life, and in particular, family-friendly programmes, which drew my attention. In these articles, the emphasis on familyfriendly programmes was being questioned. They had titles such as 'No kids? Get back to work' (Picard, 1997), 'Family-friendly backlash' (Jenner, 1994a) and 'Issues and options for childless employees' (Jenner, 1994b). In these articles the issue of equity was raised. Why is the lifestyle of one group of people (parents) valued more by management than that of others? Should single or childless employees be expected to do more shift work, travelling and holiday coverage than their co-workers with families? What efforts are being made to ensure that they are able to achieve a work/life balance? As an avid proponent of work/life balance programmes, and a working parent, I found these questions thought provoking and deserving of more analysis.
In the evocatively titled (and punctuated) 'No kids? Get back to work!' Michele Picard (1997) outlines complaints from employees in various companies who felt that they were expected to work harder then their colleagues who had families.

\section{A feeling of second-class citizenship is ex- pressed over and over again by childless workers like Louise, who complain they are expected to work later, travel more, and for- feit weekends and holidays. At the same time they are less likely to be granted flex- ible work schedules, they must justify leav- ing early, they get transferred more fre- quently, and they pay health-care premiums that are less generously subsidized that those of co-workers with families (Picard, 1997, p33).}

These sentiments are echoed even more strongly in a book by Elinor Burket entitled 'The baby boon: how familyfriendly America cheats the childless'. In the first part of the book she gives examples of how employees with children are entitled to a range of benefits not available to their childless counterparts and states that 'childless employees throughout the United States feel discriminated against and are left to silently fume' (Burket, 2000). Luckily for those silently fuming childless Americans the ChildFree Network was established in California offering support and education for childless adults. It is focusing on several issues but one of the main areas is that some workplaces are actually child-friendly rather than family-friendly.

In these companies benefits are structured with more opportunities for parents, and less flexibility for non-parents or for those workers who may be caring for elderly relatives. And, in some organisations, childless employees are expected to fill in when parents take time off for their children, yet they do not receive the same flexibility when they require time away from work (Jenner, 1994b, p7).

According to this small body of literature it would seem that those without children feel disadvantaged in several ways. They feel that their lifestyle is not valued by management as much as that of their colleagues who have children. 'The family life was considered different from a personal life. It was much more valued.' (Interview with "Louise", cited in Picard, 1997). Childless employees also feel that they are expected to cover for parents, or work less sociable hours, or travel more (Jenner, 1994a). Finally, there was the issue of benefits, both financial and non-financial, that were offered to parents more liberally than to the childless.

There are two other factors raised in the literature that are relevant to this debate. Firstly, there is an increase in the number of women choosing not to have children. 'Up to a quarter of women aged between 18 and 35 in the US 
and Europe say they do not intend to have children - and they appear to mean it' (Giddens, 1999). Dual-incomeno-kids couples are therefore becoming more common in the workplace. Secondly, despite the wave of familyfriendly policies, in many companies it is still visibility (being seen to be working hard and long) that counts. 'Everyone knows that top performers spend most of their time working. They certainly don't leave their offices at 5 o'clock' (Bailyn, 1993, p.135). Therefore, it is this 'silently fuming' underclass who are probably more likely to reap other rewards in terms of career advancement and bonus payments (Allen, Russell, \& Rush, 1994; Vannoy, 1998; Wolcott \& Glezer, 1995). Indeed, in a survey of Fortune 500 companies only 10 percent of men and one third of women in management are primary caregivers for young children (Jenner 1994b).

The last point I wish to make about the literature around family-friendly policies is the fact that little mention is made of marketing the policies in such a way that equity is ensured. Much is made of selling these initiatives to employers but the possible backlash amongst those who feel the policies are exclusive is for the most part ignored. There is one study which looks at the possible backlash in relation to on-site child care centres (Rothausen et al., 1998) and another that looks at the organisational attachment of parents and non-parents. Bailyn (1993) does talk about meeting employees' needs through a range of benefits over the life course of work, personal and family interactions. This circumvents 'attracting resentment or claims of discrimination on the part of employees who may feel they are not receiving equivalent benefits or are being subjected to conditions less favourable than those with family responsibilities' (Grossman, 1993, cited in Bailyn, 1993 p161). These references are however the exception rather than the norm. This brings us back to the questions raised earlier. Do some employees actually feel disadvantaged by work/life programmes that are familyfriendly and if so, what can be done about it?

\section{Bias}

Before progressing into an explanation of the methodology and findings, I should draw your attention to the bias I began this study with. As stated earlier I am a parent who works full time. I therefore think that family-friendly policies are essential. I also thought, upon first reading, that many of the complaints cited in the literature were trivial and showed a lack of foresight and empathy. After some more thought however, I decided I was being unfair and that those without children probably had as much right to some sort of work/life balance as those with children. The other bias I had before conducting the research was that if programmes are marketed as work/life programmes rather than simply as family-friendly, there will be a greater chance of getting buy-in from the large majority of employees. I feel that some of the findings from my research validate this point of view.

\section{Methodology}

In exploring whether there are perceived equity issues in the work/life balance programmes offered by Auckland City Council and other Auckland-based companies, and what measures could be taken to redress this I used three areas of inquiry. Firstly I examined two surveys that had already occurred, a work/life survey that was conducted in Recreation and Community Services (RACS) - a Group within Auckland City for which I work - in 1998, and the Corporate EEO survey which was undertaken in May of this year. Secondly, I conducted a survey of RACS staff to determine the composition of our workforce and their attitudes to existing programmes. I extended this survey to include any interested staff in Auckland City Environments (ACE) - another Group of Council, who share our premises but not our culture. This survey was largely of the 'tick the box' variety and therefore quantitative rather than qualitative in an attempt to get as many people to complete it as possible. (I worked under the assumption that I would get a higher return rate if people didn't have to work too hard to fill it in). I did however include some open questions so that some qualitative data could be obtained. Thirdly I sent out a small number of e-mail interviews to a non-random sample of childless people in 10 other companies. This survey comprised several openended questions and was this qualitative. I would have preferred to conduct face-to-face interviews but unfortunately ran out of time. If I was to develop this project further I would rectify this and run interviews as well as a focus group or two to gain more depth of information.

I was pleased with the response rate from RACS staff $80 \%$ of surveys were returned. Unfortunately less than $10 \%$ of ACE staff took the opportunity to reply. While the data from the ACE group is somewhat more negative than that of RACS staff, I have combined the two as being representative of Auckland City. $80 \%$ of childless people surveyed by email replied although none really took the opportunity to reply in great depth. I was also taken by surprise in that three of the respondents had to ask what was meant by a work/life balance programme, which shows how easy it is to get so caught up in jargon that you no longer notice that you are using it. Here then are the findings from this research.

\section{Findings}

An analysis of the two existing surveys proved to be of little use. The survey conducted in 1998 was intended to find out if staff were experiencing difficulty in managing work/life issues and what could be done to assist. The survey did not focus on family-friendly initiatives and only one respondent commented on any problem with peers (rather than management) being unsympathetic, and this was about pressure to work long hours rather than resentment at using any initiatives. The tenor of the survey was that RACS did reasonably well in helping staff have a work/life balance despite quite heavy workloads at times. 
The second survey was conducted by the Corporate EEO team and dealt with a huge range of EEO issues. The response to whether staff at Auckland City were able to balance work and life was generally favourable with $61 \%$ agreeing that they could achieve a balance. Heavy workloads and some lack of management support were seen as the main obstacles. There was no mention of people feeling that the programmes did not apply to them or of feeling disadvantaged in any way.

On then to the surveys conducted more recently, and with specific questions about whether or not people felt that some benefited more from work/life programmes than others. Surely here, I would find that everything was not as rosy as it appeared and there were some of those 'silently fuming' employees just waiting for the chance to air their dissatisfaction with our policies.

Sadly, for the purposes of this study, the answer appears to be no. While $52 \%$ of those surveyed felt that some people did benefit more from work/life programmes than others, only $18 \%$ felt that their workload had increased due to staff using these programmes. Even more interesting is that of those $18 \%$ over half felt that any such increase would be reciprocated should they need to take advantage of the programmes available. Several of these comments are cited below:

- Give and take should (and does) prevail

- It balances out in the long run

- It does increase but then I use the programmes and am away myself. It is a balance issue

- At times, but on all occasions I have not been concerned because I have supported the decision to support the staff member concerned.

- Not really, but swings and roundabouts - overall not

There was only one comment that mentioned the concept of a lack of equity. One staff member stated that "some tend to take advantage of benefits available, this means the remainder of the team has to cover or 'fill in' for them which after a certain amount of time seems unfair". The remainder of the comments could be divided into two areas: those stating that they didn't know whether their workloads had increased as a result of others using the programmes, and those that felt that their workloads had increased markedly due to a reduction in staffing rather than for any other reason.

As stated above, $52 \%$ felt that some staff benefited more than others from the programmes available. Those staff who were felt to benefit most were people with young and school age children, people with elder care responsibilities and solo parents.

The other interesting finding from the survey was that while only $42 \%$ of respondents had children living at home, $77 \%$ made some use of the work/life balance programmes offered. The most used programme was flexible hours with time in lieu and free health checks coming second and third respectively. Age distribution of respondents and children are showmm in Figure 1.

\section{Figure 1a. Age Distribution of Respondents}

\section{Age Distribution}

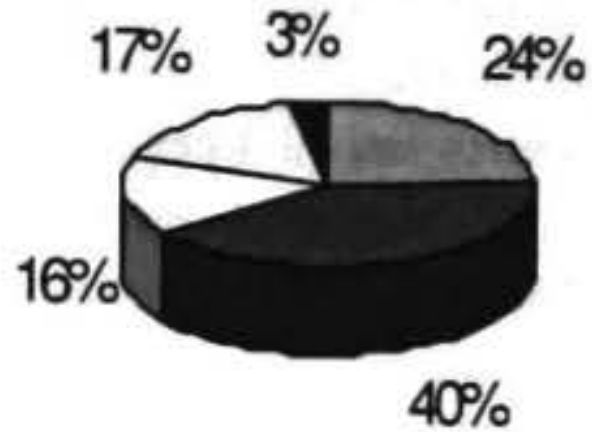

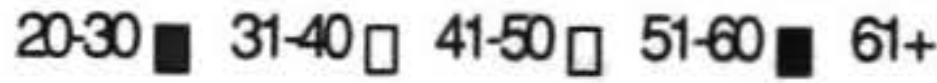

Figure 1b. Distribution of respondents by Proportion of Children Living at Home

\section{Ages of Children Living at Home}

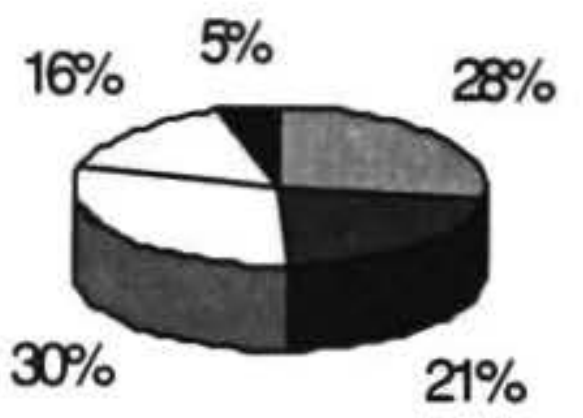

\section{5}

$6-10$ 11-15口 16-20

The qualitative data gathered in the email survey of childless people showed little evidence that childless employees feel disadvantaged. The industries covered included law, a university, the New Zealand Defence Forces, NZ Post, computing and finance. There was a range from small to large organisations and some had formal work/ life balance programmes in place while others did not. With one exception, the general consensus was that people did not feel their workload was substantially different from that of their colleagues with children. Most felt that programmes were available to them should they need them and that initiatives that allowed people to balance their work and home lives should be encouraged. One employee in the IT industry felt that his industry definitely took advantage of the fact he didn't have a family by giving him a large number of assignments that involved travel. On the other hand, he also felt that people with family 
responsibilities were probably hampered in their advancement prospects by the fact they were less willing to travel or work exceptionally long hours.

\section{Discussion}

Based on the findings of the research conducted as part of this pilot study, it would appear that, generally, employees in the firms involved do not feel disadvantaged by work/life programmes if they themselves do not have children. A slight majority of employees at Auckland City feel that some people benefit more from the range of programmes available than others, and that those who do so are largely those with family responsibilities, however there seems to be little resentment of this fact. I found that the comments made by people were often in direct contrast to those expressed by employees in the articles by Jenner and Picard.

One reason for this would obviously be that both these authors were quoting staff who did feel disadvantaged. My findings may have been different if I had actively sought out people who did feel that others were receiving more benefit from our work/life programmes than they were.

It is my belief that one of the main reasons that employees without children feel little sense of disadvantage is that we have been very careful to promote our programmes as work/life programmes, rather than family-friendly initiatives. The majority of employees who responded (77\%) said that they used one or more of the work/life programmes available. It would appear that if programmes are available to everyone then there is less resentment of those who do use them. This assumption is echoed in some of the literature. Jenner (1994) quotes Linda Marks, director of FlexGroup, a non-profit resource and research organisation who says that:

\section{It's important to stop considering a flexible work arrangement as an accommodation and start to look at it as a business strategy....when flexible work arrange- ments are available to everyone, coverage from coworkers is considered less of a "no other choice" situation and more of a re- turned favour (Jenner, 1994).}

This feeling was reflected in the 'swings and roundabouts' comments of those employees who responded to the survey, especially those staff at RACS.

Another reason I believe that feelings of inequity do not appear to be prevalent in this sample is that very few of the benefits here are of direct monetary value. Everyone at Auckland City who chooses to use the group medical scheme is subsidised to the same level. There is no subsidised childcare and the superannuation scheme is open to anyone who wants to participate. In America it would appear that many of the benefits offered to those with fami- lies are of a financial nature, for example dependent care accounts and contributions towards college funds (Jenner 1994). Indeed, in the debate about introducing paid parental leave, many of the criticisms often levelled (anecdotally anyway) at the policy are from people who do not have, or intend to have, children. While I feel this is somewhat short-sighted, it is a legitimate concern which would need to be managed by companies intending to introduce such a policy (Grover \& Crooker, 1995).

\section{Conclusion}

As stated previously, based on this small sample, New Zealanders seem more willing to support the needs of those with families, even if they do not have children themselves. They also feel able to use many of the programmes that may have originally been provided with the needs of families in mind but now apply more generally across the workforce (in Auckland City). It would also appear that a strategy to ensure that childless employees do not feel disadvantaged is to promote initiatives as being part of a work/life balance rather than a family-friendly programme. It is interesting to note that the EEO Trust has changed the name of its annual Work \& Family Awards to the Work \& Life Awards.

Despite those few articles around the area of discrimination felt by some childless employees, the vast majority of literature supported the need for family-friendly and other work/life balance initiatives. Even the 'backlash' articles supported the principle, they just felt it needed to be applied more evenly. An article titled 'The 10 million best companies to work for in America' then captured my attention. It deals largely with the proliferation of 'best company to work for' lists and what companies will do to get onto, and stay on, such lists. The part of the article that really grabbed my attention was this:

Ironically, the very policies that are supposed to ease the burden of balancing work life and personal life may be contributing to a feeling that work now weighs heavier in the balance. A parent who isn't forced to dash away at 5 p.m. to fetch a child from a day care center across town can squeeze in an extra hour of work before dashing down to pick up the child at an on-site day care facility. Workers who are allowed to work at home one day a week tend to put in longer hours as a way of proving their worth when out of sight (Stamps, 1997).

Are family-friendly policies simply a clever way of getting us to work longer after all? Perhaps a really familyfriendly policy would be one which encouraged a maximum 40 hour week, let us actually have a lunch break to do some of those errands some companies are providing concierge services for and denied access to the premises after $6 \mathrm{pm}$ and on weekends.

I was pleased to find that at Auckland City we feel that programmes apply to all staff, although some may benefit more. We are generally happy to cover for others and 
expect that this will be returned when we need to use flexible time or take time off. It was also gratifying to see that the majority of childless people surveyed felt little resentment towards their colleagues with families and felt that they could use existing programmes if necessary. The major concern raised by staff in the survey was the issue of workloads increasing due to lack of adequate resourcing and unrealistic deadlines. This is an important issue as all the family-friendly or work/life balance programmes in the world are of little use if people feel too pressured to use them.

\section{Future Research}

It is obvious that to reach any real conclusion about whether there are serious equity issues in regard to work/ life programmes in New Zealand, a much broader and more in-depth study will need to happen. There could well be differences from industry to industry and sector to sector (public versus private). The IT industry would be a very interesting area to look at - particularly as some Generation Xers (who make up a large section of IT employees) are starting families and discovering that they may no longer have the capacity or desire to work as long or travel as much. In an increasingly global market, what effect will this have on their chances and choices within their chosen profession?

If further study does establish that there is a problem in the area of equity in work/life balance programmes, the next area of research could be to establish whether this feeling has any impact on organisational attachment or performance? Will staff who feel 'discriminated' against due to their childless state be more likely to move to another firm for this reason alone, or to perform to a lesser standard than their peers who are benefiting from the programmes?

While I was looking at equity in relation to whether those without children felt they were not able to use work/life programmes to the same extent as their colleagues with children, a different equity issue was mentioned in some of the literature and by one or two of those I surveyed. Are those employees with children who use benefits such as flexible time, or who state that they are not available to travel, or put in long hours at the office discriminated against in terms of career advancement? Bailyn (1993) certainly thinks so, and further more, she would assert that this discrimination is largely gender based. She talks about the 'mommy track' - a career path where employees chose to work fewer hours, take breaks in service, and make themselves less 'visible' in the office. Other writers such as Wolcott (1995), Allen et al (1994) and Vannoy (1998) also talk about the gender imbalance in those who use family-friendly policies and the difference this can make to their careers. Are parents, and mother in particular, discriminated against in terms of career advancement in New Zealand firms?

It would also be fascinating to explore how small busi- nesses in New Zealand deal with the problems around giving their employees (and themselves) the ability to manage the often conflicting demands of work and home. The majority of New Zealand's workforce is employed in small businesses rather than in large firms with HR departments and written work/life policies. Is it harder or easier to be a working parent in a small firm and is there any sense of rivalry between workers with children and their childless counterparts for whatever benefits a small firm is able to offer?

\section{Notes}

1 HR Focus, (June 1999).

2 Equal Employment Opportunities.

3 Comment "Other team members over work beyond our normal hours, and there is often internal pressure for me to do so as well."

\section{References}

Allen, T. D., Russell, J. E. A., \& Rush, M. C. (1994). The Effects of Gender and Leave of Absence on Attributions for High Performance, Perceived Organizational Commitment, and Allocation of Organizational Rewards. Sex Roles: A Journal of Research, 31(7/8), 443-465.

Bernardi, L. M. (1999). Balancing Act: The Strategic Benefits and Legal Necessity of the Work/Home Life Balance. Canadian Manager, 24(4) 10-12.

Burkett, E (2000). The Baby Boon: How family friendly America cheats the childless. The Free Press.

Clarke, R. D. (1999). The Mother of all Balancing Acts. Black Enterprise, 30(1), 64-72.

Deutsch, M. (1975). Equity, Equality, and Need: What Determines which Value will be Used as the Basis of Distributive Justice? Journal of Social Issues, 31, 137-149.

Galinsky, E. Bond, J. T. \& Friedman, D. E. (1996). The Role of Employers in Addressing the Needs of Employed Parents. Journal of Social Issues, 52(3) $111-137$.

Giddens, A. (1999). BBC Reith Lectures, Lecture 4 -Family. BBC Online Network

Grover, S. L. and Crooker, K. J. (1995). Who Appreciates Family-Friendly Human Resource Policies: The Impact of Family-Friendly Policies on the Organizational Attachment of Parents and NonParents. Personnel Psychology, 48(2), 271-288. 
Hooks, K. L. (1996). Diversity, Family Issues and the Big 6. Journal of Accountancy, 182(1), 51-56.

Jenner, L. (1994a). Family-Friendly Backlash. Management Review, 83(5), 7.

Jenner, L. (1994b). Issues and Options for Childless Employees. HR Focus, 71(3), 22/23.

Kehan, M. M. (2000). Kid-Friendly Incentives. Incentive, 174(1), 59-61.

Kramar, R. (1997). Developing and Implementing Work and Family Policies: The Implications for Human Resource Policies. Asia Pacific Journal of Human Resources, 35(3), 1-18.

Law, G. (1998). Families at Work. Management-Auckland, 45(9), 36-40.

Picard, M. (1997). No kids? Get Back to Work! Training, 34(9), 33-40.

Rothausen, T. J., Gonzalez, J. A., Clarke, N. E., \& O'Dell, L. L. (1998). Family-Freindly Backlash Fact or Fiction: The Case of Organizations' onsite Child Care Centers. Personnel Psychology, 51(3) 685-706.

Schrage, M. (1999). Family-Friendly' Firms will find that no Good Deeds go Unpunished. Fortune, 139(10), 294.

Stamps, D. (1997). The 10 million Best Companies to Work for in America. Training, 34(12), 42-44.

Vannoy, D. (1998). Problems and Prospects for more Effective Integration of Work and Family in the Twenty-First Century. D. Vannoy \& P. Dubeck (Eds.), Challenges for work and family in the twenty-first century. New York: Aldine De Gruyter.

Vannoy, D. and Dubeck, P. (eds.). (1998). Challenges for work and family in the twenty-first century. New York: Aldine De Gruyter.

Wolcott, L., \& Glezer, H. (1995). Work and Family Life: Achieving Integration. Melbourne: Australian Institute of Family Studies.

\section{Author}

\section{Avette Kelly}

Human Resources Development Consultant

Recreation and Development Support

Recreation and Community Services

Auckland City Council

Private Bag 92516

Wellesley Street

Auckland

kella@akcity.govt.nz 